\title{
5.INFORIMACION BIBLIOGRAFICA
}

\section{TORRADO, Susana. Estructura Social de la Argentina: 1945-1983. Eds. de la Flor. Bue- nos Aires, 1992, 556 páginas.}

La polémica acerca de la profundidad y la dirección de los cambios en la Estructura Social en la historia más reciente de América Latina puede considerarse, sin exageraciones, como una de las más vivas y trascendentales dentro del panorama actual de las Ciencias Sociales en aquel Subcontinente. En realidad, nada tiene de extraño puesto que a través de ella no está sino evaluándose la validez de los modelos económicos impulsados en los últimos decenios. Por ejemplo, es precisamente la evidencia de la creciente acentuación de las desigualdades sociales uno de los factores fundamentales de cuestionamiento de las políticas económicas denominadas primero «de ajuste» y últimamente «de postajuste». Políticas que en ciertos países latinoamericanos están provocando una evolución aparentemente favorable de las variables macroeconómicas, pero con un proceso de dualización en la Estructura Social tan extremo, que pone en entredicho de forma global la validez de las recetas aplicadas.

En ese sentido, el trabajo de Susana Torrado resulta especialmente significativo. La autora se plantea el análisis de la evolución de la Estructura Social argentina en un período tan decisivo para la historia reciente de aquel país como es el que transcurre entre 1945 y 1983 . Y lo realiza con una meticulosidad y autoexigencia teórica y metodológica que deben ser destacadas.

En un terreno habitualmente tan poco definido y lleno de sobreentendido como el del estudio de la Estructura Social, la autora se atreve a desarrollar explícitamente cuáles son sus posicionamientos de partida y a especificar en función de ellos su estrategia metodológica. Así, Susana Torrado plantea el análisis de los cambios de la Estructura Social argentina, identificando ésta con la Estructura de Clases Sociales. La misma es relacionada en cada momento con la evolución de los distintos modelos de acumulación que se suceden en este período. Torrado diferencia tres grandes modelos, que se corresponderían a su vez con tres tipos de estrategia de desarrollo.

El modelo justicialista (1945-1955) se caracterizaría por una novedosa alianza de clases, encabezada por Perón, entre los pequeños y medianos empresarios industriales y la clase obrera. Políticas distribucionistas en lo social e industrialización sustitutiva de importaciones serían los rasgos más sobresalientes de este período.

Este modelo dejaría paso al que Torrado denomina como desarrollista (1958-1972); en él, la alianza de clases fundamental se establecería entre la burguesía industrial nacional y el capital extranjero. A diferencia de momentos anteriores, y aun cuando la industria continúa ocupando un papel central en la estrategia de desarrollo, hay una tendencia acusada a la concentración de ingresos.

Por último, el modelo aperturista (1976-1983) se desplegará tras el golpe militar, estableciéndose una alianza entre el estamento castrense, los sectores de la burguesía nacional que concentraban una mayor parte de la riqueza y las empresas transnacionales. Son años de profundísimas transformaciones, puesto que se cuestiona el proceso industrializador como objetivo decisivo en el camino hacia el desarrollo. A la vez, se endurecen las condiciones laborales de los trabajadores, poniéndose en marcha una política de represión de un movimiento obrero que había alcanzado altas cotas organizativas reivindicativas. Consecuencia de todo ello se produjo un importante crecimiento de la desigualdad social.

A lo largo del libro se realiza un análisis exhaustivo de la fuerza de trabajo argentina, utilizándose un amplísimo caudal de información. De por sí, únicamente esto último convertiría el texto en muy importante, dada la gran dispersión y compleja accesibilidad a muchos de los datos recogidos por la autora. Pero además, la utilización que se da a esta información es ejemplar, puesto que Susana Torrado mantiene una actitud constante de alerta epistemológica que se refleja en el proceso de elaboración de los indicadores estadísticos. En toda investigación de este tipo, aunque no siempre se tenga en cuenta, las características de los datos disponibles condicionan la construcción, la pertinencia temporal y las posibilidades de comparabilidad de los indicadores.

Quizá la única carencia que se encuentre en el libro sea la falta de alguna referencia cualitativa a los procesos analizados. Ello podría haberle dado al estudio una riqueza que la información estadística, por sus limitaciones analíticas inherentes, no puede ofrecer. La autora ha sido consciente de ello y en el propio texto se defiende, manteniendo que pretende centrarse exclusivamente en la Estructura de Clases y no en lo que denomina como Relaciones de Clase. Argumento escasa- 
mente convincente, puesto que dicha división es de una extremada rigidez, con planteamientos excesivamente «objetivistas».

En fin, y para concluir, nos encontramos frente a un libro de lectura muy recomendable para todos aquellos que pretendan adentrarse en el conocimiento de la Estructura Social argentina o que, en general, estén interesados en los problemas que plantea el estudio de la Estructura Social. Cabe sólo desear que Susana Torrado aproveche pronto la información del Censo de 1991 para analizar los cambios en la Estructura Social durante estos últimos años. En principio, diversos indicios parecen apuntar a que, a pesar de la vuelta de la democracia formal, el despliegue del modelo de acumulación aperturista ha continuado con toda intensidad, con las consecuencias de empobrecimiento y dualización social conocidas.

María Luisa Loures Seoane

\section{NOHLEN, D. (ed.). Elecciones y Sistemas de Partidos en América Latina. IIDH-CAPEL, San José, mayo 1993, 516 págs.}

El balance que la década de los 80 ha representado para América Latina arroja un cuadro con claroscuros. En el aspecto socioeconómico, ha sido calificado como la «década perdida». Sin embargo, en el aspecto político, la década representa el fin de las dictaduras militares de los 70 y el advenimiento de una oleada democratizadora. Para la Ciencia Política, esta circunstancia ha provocado un enorme interés por todo lo relacionado con la representación política. El binomio elecciones y sistemas de partidos - ejes temáticos de este texto - constituye uno de los factores de mayor relevancia a la hora de analizar dicha representación.

En efecto, la limpieza de los procesos electorales constituye el criterio más importante que discrimina las distintas formas de gobierno en dos grandes grupos: las democráticas y las autoritarias. Pero si son las elecciones las que originan la representación política democrática, el segundo elemento del binomio, los sistemas de partidos, proporciona la fortaleza y funcionalidad a la representación al mismo tiempo que influye decisivamente en el funcionamiento del sistema de gobierno.

En el área de conocimiento de gobierno comparado la literatura sobre esta temática ha producido en los últimos tiempos un notable acervo. Ahora bien, la mayor parte de estos estudios se refieren abrumadoramente a los países miembros de la OCDE. Por tanto, el enorme interés que en la reflexión politológica latinoamericana detectábamos en estos temas desafortunadamente no se ha traducido en el volumen de producción de estudios que sería deseable.

En este sentido, y en palabras de su editor, «este libro aspira a cubrir la necesidad de enfocar la representación política en América Latina de manera amplia y multidisciplinaria». Tarea que se convierte en un requisito imprescindible para la inclusión de América Latina en investigaciones comparativas.

Los diversos artículos que componen el texto aparecen agrupados en cuatro partes:

1) Régimen electoral: Desarrollo legislativo y administrativo. Bajo este título aparecen los cinco artículos que componen la primera parte y que tratan de cuestiones como el sufragio y su desarrollo, los órganos y registros electorales y la reglamentación de las candidaturas.

El primero de los artículos aparece firmado por Victoria Juárez Guerra y es un análisis comparado de la representación política en tres países de la región, Colombia, Ecuador y Venezuela, durante los primeros movimientos de independencia. Es el único artículo que se refiere a la historia del siglo XIX en un texto que se caracteriza precisamente por focalizar su atención en los últimos diez años.

Juan Fernando Jaramilla, autor del segundo de los artículos, analiza comparativamente los organismos encargados de la organización, dirección y vigilancia de los procesos electorales en tres países, Argentina, Costa Rica y República Dominicana. El objetivo consiste en explorar la relación existente entre las cortes electorales de los tres países y el patrimonio de credibilidad de las elecciones en los mismos.

Continúa esta primera parte con la contribución de Marta León-Roesch que trata acerca de la funcionalidad del registro electoral en los siguiente países latinoamericanos: Argentina, Colombia, Costa Rica, Chile y Venezuela. Se mide esa funcionalidad tomando cinco elementos: 1) La forma de organización del registro electoral. 2) Cuál es el criterio utilizado para la elaboración del registro electoral. 3) Proceso de inscripción del elector. 4) Mecanismo de actualización y depuración del registro; y 5) Mecanismos de control de las inscripciones en el registro electoral.

El penúltimo trabajo de esta primera parte está realizado por Jorge Mario García Laguardia. Se trata de un informe preparado por un consultor en el que se vierten análisis sobre el Registro Civil en Nicaragua y se formulan recomendaciones para la elaboración de un registro electoral permanente.

Finalmente Xiomara Navas Carbo clasifica de forma sistematizada las distintas regulaciones, contenidas en las constitu- 
ciones, leyes electorales y leyes de partidos de 17 países latinoamericanos que versan sobre la financiación de los partidos políticos y las campañas electorales.

2) Elecciones y desarrollo político. Aspectos institucionales y conceptuales. La segunda parte de la obra agrupa a tres artículos en los que se abordan cuestiones relacionada con los distintos tipo de elecciones existentes (semicompetitivas, competitivas, de apertura), así como con la campaña electoral.

La primera de estas contribuciones es de Michael Krennerich. En ella se confrontan los procesos electorales verificados en Nicaragua, El Salvador y Guatemala antes y durante la transición (llevada a cabo en los años 80) investigando en qué se diferencian. En el fondo, se plantea la pregunta de hasta qué punto las elecciones realizadas durante los cambios de régimen satisfacen las «reglas del juego» dentro de la transición liberal-pluralista y cómo están limitadas por la «herencia autoritaria». El concepto de elecciones competitivas sirve como herramienta analítica.

En el segundo artículo, Rafael López Pintor y Dieter Nohlen, analizan el tipo de cambio de régimen que ocurrió en Nicaragua tras las elecciones de febrero de 1990 y la naturaleza del proceso electoral que llegó a traducirse en un cambio político poco esperado. Los autores introducen el concepto de «elecciones de apertura» para poder hacer frente a una nueva clase de experiencia electoral.

Clausura esta segunda parte el texto de Larissa Adler Lomnitz, Claudio Lomnitz A. e Ilya Adler. Presenta algunos hallazgos e ideas que surgieron a partir del estudio etnográfico de la campaña presidencial (1988) del partido Revolucionario Institucional de México. Se estudian los elementos fundamentales de la organización de los actos públicos de la campaña de Carlos Salinas, así como sus posibles raíces y razones.

3) Sistemas de partidos y desarrollo político. La tercera parte de la obra da cabida al segundo de los elementos del binomio al que hacíamos referencia más atrás. Concretamente, el sistema de partidos políticos, su dinámica y su relación con la consolidación de la democracia, así como la experiencia del modelo inglés de sistema político en el mundo caribeño, son los temas sobre los que vierten sus reflexiones los tres artículos de esta parte.

Bernhard Thibaut se concentra en ciertos aspectos del desarrollo político de Costa Rica, a partir de la II República (1948), y de Venezuela, a partir de la instauración de la democracia (1958). En primer lugar se presentan diversos enfoques explicativos de la estabilidad política (del sistema político) en ambos países, pasando luego a una comparación estructural sistemática.

Petra Bendel se ocupa del análisis de los partidos políticos y de los sistemas de partidos en Centroamérica. Su objetivo es reflexionar en torno al alcance de la terminología y la metodología de investigación europeas sobre sistema de partidos cuando se aplican al contexto centroamericano.

En el último artículo de esta tercera parte, Bernd Hillebrands realiza una comparación de los sistemas políticos de los doce estados caribeños miembros de la Commonwealth, cuestionando sobre todo la constancia y los cambios en su evolución.

4. Instituciones, partidos y gobernabilidad. La parte final de la obra aborda la relación que existe entre representación política, forma de gobierno y gobernabilidad a través de tres contribuciones.

Dieter Nohlen reflexiona sobre la relación existente entre sistemas electorales y gobernabilidad, específicamente los efectos de los sistemas electorales en la gobernabilidad, que pasan a través del sistema de partidos y su relación con las instituciones políticas en América Latina.

Bolivar Lamounier pone en relación tres variables para el caso de Brasil: parlamento, sistema electoral y gobernabilidad. Los objetivos son: primero, organizar conceptualmente los argumentos sobre la conexión entre el sistema de gobierno y la gobernabilidad; segundo, discutir cuál será el sistema electoral conveniente en el caso de que el parlamento sea implantado.

Por último, Liliana de Riz y Jorge Feldman firman el trabajo que pone fin a la obra. El propósito de este trabajo es analizar la relación entre el gobierno y su partida durante la gestión de Raúl Alfonsín. El foco de interés es la relación entre los objetivos del gobierno de Alfonsín, de fortificar la democracia y manejar eficazmente la economía, por una parte, y los trade-offs entre el gobierno y los intereses políticos de su partido, por otra.

Fernando Harto de Vera

\section{MONTALVO, Atilio. Los Acuerdos de Paz un año después. CINAS, S. Salvador, junio 1993, 260 págs.}

La firma de los Acuerdos de Chapultepec, el 16 de enero de 1992, pusieron fin a la guerra civil que asoló El Salvador durante más de diez años. El período transcurrido entre esta fecha y el mes de diciembre de ese mismo año, momento en el que el FMLM desmontó su estructura militar, constituyó un hito en la reciente historia salvadoreña. Fueron doce meses en 
los que en un proceso no exento de tensiones comenzaron a echar a andar los compromisos contraídos por ambas partes en México.

En este contexto, a un año de haber transcurrido la vigencia de los Acuerdos de Paz (enero 1993), Atilio Montalvo se propuso la tarea de realizar una serie de seis entrevistas para recabar opiniones cualificadas acerca de la marcha de los acuerdos. Uno de los aciertos del autor consiste en la cuidada selección de los entrevistados, todos ellos personalidades de indudable relevancia.

Iqbal Riza se desempeñó durante casi dos años como Jefe de la Misión de Observadores de ONUSAL y expresa en el texto sus opiniones sobre los principales acuerdos, principalmente respecto al papel verificador de ONUSAL.

David Escobar Galindo, quien es una personalidad del quehacer intelectual salvadoreño, formó parte de la Comisión Negociadora del gobierno y trabajó por más de dos años en las conversaciones de paz. Actualmente forma parte del Consejo Académico de la Academia Militar de las Fuerzas Armadas.

El comandante Schfick Jorge Handal, actualmente Coordinador General del partido FMLM, encabezó la Comisión Negociadora del FMLM en las conversaciones de paz por más de dos años y trabajó en la Comisión de Seguimiento de la ejecución de los Acuerdos en el último año.

Gloria Salguero Gross es vicepresidenta de la Asamblea Legislativa y dirigente del partido en el gobierno (ARENA); ha trabajado desde la fundación de COPAZ en la supervisión de los Acuerdos de Paz.

Vistor Valle, Secretario General del Partido Socialdemócrata MNR; trabajó en los últimos años en la formación de la primera interpartidaria hasta la conformación de COPAZ, en donde también ha desempeñado su trabajo en la supervisión de los Acuerdos de Paz y además formó parte del Consejo Académico de la Academia Nacional de Seguridad Pública.

Salvador Samayoa formó parte de la Comisión Negociadora del FMLN en las conversaciones de paz y durante diez años formó parte de la Comisión Político-diplomática del Frente. Actualmente desempeña su trabajo en la Comisión de Seguimiento de la ejecución de los Acuerdos de Paz.

El autor, con experiencia y dominio de la materia, logra con los entrevistados, a través de una conversación fluida, abordar de una manera objetiva los asuntos más polémicos y candentes de los Acuerdos y, por medio de un minucioso trabajo, logra hilvanar rigurosamente todas las opiniones ordenándolas tema por tema para una mayor facilidad de lectura. Junto con la elección de los entrevistados, la selección de los temas es otro de los aciertos del autor. Del prolijo conjunto de los más de cien acuerdos se seleccionan aquellos aspectos de mayor interés, como son los referentes a las garantías de cumplimiento, el papel verificador de ONUSAL, las Fuerzas Armadas, la Comisión Ad Hoc, la Comisión de la Verdad, la transformación del FMLN en partido político, el aspecto económico social, el tema agrario y la Policía Nacional Civil.

El método empleado en el libro es el de hacer en la introducción una breve reseña de los principales acuerdos ejecutados y cómo se ven a un año después de iniciados. Luego se agrupan las seis entrevistas en las temáticas más importantes de los Acuerdos, en las cuales todos opinan alrededor de cada tema específico.

El trabajo se realizó entre enero y marzo de 1993. Para complementar la publicación se incluye un anexo con documentos sobre la Ley de Amnistía y un resumen sobre las resoluciones de la Comisión de la Verdad.

Fernando Harto de Vera

\section{ECHEGARAY, Fabián; RAIMONDO, Ezequiel. Desencanto político, transición y demo- cracia. Biblioteca Política Argentina. Centro Editor de América Latina, Buenos Aires, 1987, 141 págs.}

Reseñar un libro publicado hace ya seis años tiene, en este caso, por lo menos tres motivos de valor: por una parte, el tema de que se ocupa. El desencanto político viene llenando el modestísimo espacio de un ítem en la agenda de las cuestiones objeto de estudio de la politología contemporánea; faltan trabajos sistemáticos sobre un asunto que reviste la entidad de problema teórico. En segundo lugar, es de notoriedad que los fenómenos de cinismo político, apatía y desencanto, vienen conformando el «piso» cultural donde se posan las democracias de la postransición; en este sentido, se peca por defecto de la realidad. Por último, deben destacarse la calidad teórica del trabajo emprendido, la construcción de un marco analítico novedoso en base a solventes aportes ajenos y propios, y finalmente, la preocupación que anima cada una de las páginas: la superviviencia de la democracia.

El desencanto se caracteriza por la desafección de los ciudadanos por la «cosa pública», su reclusión voluntaria, repliegue y ensimismamiento, todo lo cual prueba a su vez, un tipo de distribución del interés emotivo orientada al mundo de los privado. El desprecio por lo público y por la política, hace carne en la «renuncia, que se traduce en desparticipación y el 
consiguiente inicio del proceso de despolitización, que naciendo de la intimidad se multiplica en el magma social pudiendo llegar a ser masivo». Los confines del mundo posible se colocan desde lo social, en los límites de la esfera privada, como espacio contestario y como muralla defensiva.

El desencanto político está íntimamente vinculado a la «cuestión democrática» en un doble sentido: primeramente porque es posible sólo en condiciones de libertad y «espacios ampliados», y da cuenta de un acto de la voluntad, de una opción legítima, frente a la incertidumbre propia de una situación de «guerra de promesas» diluida. La otra relación tiene que ver con el vaciamiento de poder democrático: el especial redimensionamiento de lo público que aquel secreto compartido genera, convierte a la política en una cuestión de «políticos profesionales», de «élites». Viéndose frustrada toda posibilidad de participación - participaciòn que es concebida como indispensable al interior de una concepciñón íntima e «ideal» de la política-, se finiquita todo protagonismo y fiscalización ciudadanas y se protesta de este modo contra la moralidad de la política real.

Pero el desencanto no es eterno, es dinámico y cíclico. Es recomponible como reencantamiento, como posibilidad de un mesías fundador de una nueva vivencia mágica. El ciclo encanto-desencantamiento-reencantamiento no permite clausurar la mentalidad desencantada como realidad democrática una vez acabada la euforia primitiva; el ciclo es dinámico y revela cuán conectadas están las utopías con la búsqueda de la felicidad, cuán dependiente es tal ciclo universal de la racionalidad de pasiones (en este punto, los autores integran el rescate hirschmaniano de las pasiones como inmanentes a la racionalidad humana).

Es en esta relación entre cinismo político primero, desencanto des-participativo luego, y democracia, donde pesa cierta acusación a la teoría de la cultura política de los años 50. Desde esta perspectiva, cierta dosis de apatía ciudadana era imprescindible para la estabilidad democrática. Echegaray y Raimondo muestran la sustancial diferencia entre la apatía como opción política positiva - y conservadora - respecto de la política, que no interpela la legitimidad del régimen (la apatía es «una forma de expresión política elegida» que no presupone agresión política previa, ni expulsión, ni insatisfacción), y el desencanto, que «se recluye en la privacidad más porque no encuentra dónde volcar su participación con un subjetivo sentimiento de positividad, que porque en realidad prefiera conscientemente abandonar la arena política). El desencanto erosiona la legitimidad de la política y en ese sentido no puede asimilarse al supuesto sustrato cultural que subyace necesariamente a toda democracia estable. La inclinación a disfrazar el desencanto tras los ropajes de la apatía, de hecho legitima (aventuradamente), deslizamientos no democráticos que acaecen en las democracias «estables».

La sensibilidad del régimen a este clima psicológico perverso es mayor en procesos de transición democrática que en el caso de democracias consolidadas; precisamente porque consolidación implica descontar que un encantamiento mínimo está asegurado, que «la participación política mínima indispensable para el mantenimiento del edificio está dada». Cuando tal umbral es transgredido, la posibilidad de quiebra está prefigurada.

Específicamente, la paralela «modernización del consumo», la socialización del individuo en el consumo, alimenta el desencanto, absorbe de antemano las energías sociales hacia el mundo de lo privado, recreando un espacio político-público limitado a la administración en base a principios económico-privados. El desencanto cuestiona las diferentes formas institucionales de dessubjetivización (la intermediación, la representación), y termina abreviando por la lógica de la mercantilización, en la ideología liberal-autoritaria, independientemente coincidente. Tras sucesivas experiencias de demandas y apoyos distorsionados o desvirtuados, la reclusión en el ámbito privado, únicamente demanda por la conservación del mercado y la eliminación de opiniones divergentes que sólo pueden conducir a un aumento de la inseguridad ciudadana, a la propagación de la alergia producida por el desorden.

Pero no solamente una ruptura democrática es propiciada desde la entronización de nuevos intereses; la búsqueda de propuestas que oferten soluciones mágicas es también una probable salida del desencanto; por otra parte, cuando la cultura política se presenta como un verdadero «stratum» previo al contacto con la política, las utopías radicalizadas inscritas en su trama, representan alternativas reales de huida exasperante del desencanto. En situaciones de mero reencantamiento, la protesta, la violencia en el trato interpersonal, la agresividad individual y las manifestaciones anti-sistema, constituyen exhibiciones de oposición desleal al orden.

El desencanto es un fenómeno amplio: no es solamente un proceso que va de lo particular a lo colectivo, sino que como conformación particular de la subjetividad social que llega a ser, se resiente de las reglas propiamente políticas, pero finalmente de todas las reglas (sociales) que vienen pautando el comportamiento colectivo, de todos los principios que normatizan la actuación pública de los individuos. La propensión a la ruptura muestra entonces su latente ubicuidad.

La existencia de «democracias desencantadas» permite a los autores asertar que existen gobiernos democráticos, pero no regímenes democráticos acabados. Del desencanto surge la desdemocratización. Si bien ello no implica una quiebra de la legalidad democrática, ni el súbito resucitar del autoritarismo, sí supone la democradura, en concomitancia con las reflexiones de Schmitter, es decir, un «régimen electoral con restricciones al acceso y a los derechos de los ciudadanos». La desdemocratización es vista entonces, no como autoritarismo, sino como «la distorsión (por relajamiento o degeneración) de los alineamientos democráticos en la práctica; desdemocratización que dispensa las credibilidades democráticas, a la vez que reduce la escena política». La articulación definitivamene autoritaria por parte de quienes asumen el callado reclamo social, puede devenir real en segundo término, y fácilmente una vez que la masa frustrada ha puesto ya coto a la democratización. 
No obstante, la «privatización voluntaria» que constituye el desencanto, es capaz de abrir las puertas a una interpretación más optimista. El ensimismamiento hiperindividualista podría desembocar en una forma de participación social defensiva, proteccionista de lo privado, en rescate de los valores y certidumbres auténticas y sustanciales y en pro de la solución de los problemas más cercanos y más íntimos. Un tipo de participación que nada tiene que ver con la lógica de la participación política - es antipolítica-, no con la del mercado, ni con las formas de compromiso entre política y economía; más bien se trataría de la invención de nuevos contenidos puestos a llenar los espacios de un imaginario político en crisis, de un llamado al mundo político para su reformulación lenta y trabajosa desde la más profunda privacidad.

Gabriela Delamata

\section{BESAVE BENITEZ, Agustín. México mestizo. Análisis del nacionalismo mexicano en torno a la mestizofilia de Andrés Molina Enríquez. Fondo de Cultura Económica, México, 1992, 165 págs.}

Este libro constituye una investigación de carácter histórico teórico sobre el fenómeno de la mestizofilia, desde la perspectiva de la historia de las ideas y de pensamiento en la línea que D. Brading (1) atribuye a W. Wolf, El Florescano y F. Chevalier, pero también a E. Gruening, N. L. Weten y C. C. Cumberland y, sobre todo, F. Tannembaum. Analiza las principales tesis que se han elaborado desde los orígenes de esta corriente desde 1503 — cuando el gobernador Ovando recibió en Santo Domingo la instrucción real de procurar el casamiento de españoles con indios, a fin de que éstos se transformaran en «gente de razón»- con un análisis detenido de Andrés Molina Enríquez, que en 1895 comienza a crear su pensamiento mestizófilo, constituyendo sus obras uno de los estudios más importantes y sólidos de la problemática social mexicana, hasta llegar a los autores del México postrevolucionario, en torno a 1934.

El marco teórico del texto hace referencia a los conceptos de identidad nacional, nación, corriente nacionalista - pero delimitando esta última al proceso de constitución del Estado partiendo del concepto de nación englobante y excluyente, la contraposición raza-cultura y el eurocentrismo-. Plantea su tesis en la mestizofilia como respuesta a los interrogantes de identidad nacional, que son el reflejo del imaginario político en distintas épocas y ante distintos acontecimientos políticos.

El autor utiliza el método comparativo con la obra de Molina Enríquez y la de otros pensadores, confrontando los instrumentos teóricos de su argumentación mediante sus textos originales, así como realizando un análisis de los mismos y evaluando su contribución a la historia de las ideas de México.

El libro está estructurado en tres partes: «Los orígenes de la corriente mestizófila», «Andrés Molina Enríquez o la mistificación del mestizo» y «El desenlace actual de la mestizofilia». En la primera, la relación con el mestizo se analiza desde la actitud de las élites coloniales; se estudian los padres de la mestizofilia, Francisco Pimentel,Vicente Riva Palacio, Justo Sierra, la posición de los liberales decimonónicos ante el indio y la cuestión racial y la valoración del Porfiriato de lo indígena representada por Gabino Barreda y Francisco Bulnes. La segunda parte está dedicada a Molina Enríquez, su vida y obra, la exposición y la evaluación crítica de la misma desde una doble perspectiva: desde la de las teorías en que se inspira y desde las contradicciones metodológicas, teniendo en cuenta los frutos que recogió la tesis en su época y los que aún sguen presentes. La tercera parte trata del boom de la mestizofilia entre los ideólogos revolucionarios, analizando las tesis de Manuel Gamío y José Vasconcelos y el México postrevolucionario del grupo Hiperión, Leopoldo Zea, Alfonso Reyes, Jorge Carrión, etcétera. Las conclusiones y una bibliografía circunscrita a los pensadores estudiados, su obra y su eco, así como la de quienes se han ocupado de ellos, cierra este interesante estudio.

El autor pasa a constatar la laguna en la bibliografía sobre el nacionalismo mestizo, sobre las aportaciones mestizófilas en México, aunque haciendo la salvedad desde la perspectiva indigenista de Luis Villore, en Los grandes momentos del indigenismo en México (2), y de Aguirre Beltrán en «Oposición de raza y cultura en el pensamiento antropológico mexicano», «Un postulado de política indigenista» y «Los símbolos étnicos de la identidad nacional» (3). Por ello ha tratado de resumir el estado de la cuestión con un breve resumen de las principales tesis mestizófilas mexicanas, considerando la más rica de ellas y objeto de análisis más detallado, la de Molina Enríquez.

Besave define la mestizofilia, en sentido amplio, como la idea de que el fenómeno del mestizaje — la mezcla de razas y/o culturas- es un hecho deseable, y sostiene que la tesis central de Andrés Molina Enríquez parte de la premisa que considera a los mestizos de México como a los mexicanos por antonomasia, los auténticos depositarios de la mexicanidad, y pretende demostrar histórica y "socioetnológicamente» que México no puede convertirse en una nación desarrollada y próspera mientras no culmine su proceso de mestizaje, mediante la reducción a una de todas las minorías de las mezclas entre indios y criollos.

(1)) D. Brading, «Modernización e ideologia, 1850-1940», X Congreso de AHILA, Leipzig, 21-24 de octubre de 1993.

(2)) Ed. de la Casa Chata, México, 1979, pp. 175-223

(3)) Aguirre Beltrán, G., Obra polémica, SEP, INAH, México, 1975. 
A diferencia de lo que sucede en Europa, en el ámbito de los nacionalismos, en América Latina y en México también, el fenómeno fue contrario: primero se obtuvieron los Estados y luego se intentó crear las naciones, pero los pueblos carecían de conciencia nacional, siendo la idea de nacionalidad patrimonio exclusivo de las élites coloniales. Al principio la corriente mestizófila subrayaba los aspectos negativos del mestizaje, haciendo de la mezcla de razas la causa del desorden de México; luego evolucionó hacia los aspectos positivos del ser mestizo hasta llegar a propugnar el mestizaje como la quintaesencia de la mexicanidad.

Las variables estructurales que utiliza en la construcción del modelo socioetnológico del mestizaje son de carácter racial: mestizo, indio y criollo; se evoluciona luego hacia la variable económica de la propiedad rural, la política del liderazgo, para llegar a la cultural.

Por lo que se refiere a Molina Enríquez, Besave lo considera un progresista social con una concepción tenológica del devenir histórico, dado que asocia a los indígenas a conservadores y no distingue al principio entre criollos y mestizos, deduciendo que siente un respeto por aquéllos. Con La Reforma y Juárez (1906), atribuye al Plan de Ayutla, cuando Juan Alvarez derrocó a Santa Anna, el inicio de la etapa de apropiación del poder por los mestizos y su consolidación al Plan de Tuxtepec de Díaz, en 1876 se orienta hacia la mestizofilia. Las premisas de su tesis se resumen en: sólo erradicando las diferencias raciales se puede construir una nación viable; existe una «zona de cereales», que hará del mestizo el dueño de América.

Su tesis contiene una contradicción continua; si, como Molina Enríquez sostiene, no existe separación absoluta de razas, ¿por qué trata de ajustar la realidad a sus esquemas raciales?

Enfoca el problema de la tendencia de la tierra con el prisma histórico de la lucha racial, y más tarde le sirve también para plasmar a los grupos étnicos, para concluir que los modos de propiedad de la tierra son reductos de los grupos raciales.

Es la producción agrícola, de cereales, la que determina la existencia de las sociedades y la posesión de la tierra en época colonial la que señala la formación del mestizo. Fue un mestizaje étnico el que luego experimentó ajustes. Ejemplifica el hecho de que con la colonia sólo pocos tuvieron acceso a la tierra; los más se fueron convirtiendo en mstizos. Con la Independencia los criollos reemplazaron a los españoles convirtiéndose en criollos-señores; los criollos-clero, los mestizos profesionales y los «revolucionarios»; los indígenas que sufrieron un leve ascenso social gracias a que los mestizos abandonaron ocupaciones detentadas precedentemente. A todos ellos se vino a añadir el grupo de los criollos nuevos o liberales.

Las ventajas del mestizo derivan de su naturaleza y son producto de la selección. Es en Los grandes problemas nacionales (1908) en donde Molina Enríquez empieza a elaborar su teoría del mestizaje, en base a la tesis evolucionista, resultado de la selección, individual y colectiva, y darwinismo racial es el que provoca la destrucción o la mezcla de unas razas con otras. Teórico del nacionalismo, o de la mestizofilia como respuesta al interrogante de la identidad nacional y más conocido por sus ideas agrarias y presidencialistas, sin embargo realmente preocupado por la conformación de una nacionalidad verdaderamente mexicana. Los otros temas, la propiedad rural y el liderazgo político, son medios para alcanzar la unificación de la patria mestiza: su agrarismo sería menos si hubiera hacendados y peones convertidos en mestizos; como lo sería su determinación dictatorial si el mestizaje hubiera acabado con las diferencias étnicas. La posesión de la tierra por parte de los mestizos los acercaba a los criollos, proceso que llevaba a culminar el mestizaje. Las fases de desintegración racial y económica y su transformación hacia una sola corresponden al período de la Independencia y el Porfiriato, ya que Porfirio Díaz, mestizo y conocedor de su raza había llevado al equilibrio racial, habiendo arrebatado las tierras a las clases altas. Esta idea la completa en La revolución agraria (1932), pero añade otras dos nuevas ideas a su tesis: concibe al mundo dividido en oriental y occidental y atribuye la selección racial a la generación de los dos grupos humanos; la independencia hubiera sido otra si indios y mestizos hubieran desposeído a los criollos porque con ello hubieran nutrido a su raza y formado una nueva nacionalidad. El Porfiriato extirpó los cacicazgos y mantuvo la preponderancia de los mestizos, pero decayó por haber cedido a las lisonjas de las criollas. Y si la reforma agraria no prosperó, como debía, fue a causa de que había demasiado criollos aún entre los encargados de llevarla adelante. Pero el cardenismo pronto devolvió la fe a los mestizos. Sus tesis mestizófilas son ahora antihispánicas, de defensa del indígena, de ruptura del evolucionismo a favor de un progreso multidimensional. Respecto a la anterior obra divide a los grupos en indio-mestizos y criollo-mestizos, e introduce a México en el terreno internacional, dado que las acciones extranjeras con capaces de influir en el desarrollo del país. La lógica de Molina es que para que México sea grande tiene que culminar el mestizaje. El acercamiento del indio al mestizo es casi un hecho; el del criollo sólo se puede lograr con la reforma agraria que ascenderá al mestizo a clase proletaria, lo que se conseguirá sólo con un fuerte poder dictatorial. Agrarismo y autoritarismo son los requisitos fundamentales del México mestizo.

Sus ideas representan la transición del Porfiriato a la revolución mexicana, anticipándose al establecimiento del presidencialismo, prefiguración del nacionalismo cultural revolucionario. Influyó sobre José Vasconcelos, con su defensa del muralismo y forja de los movimientos culturales mexicanos.

Sin embargo, el fracaso del Po firiato, el poderoso flujo de movimientos populares, como el zapatismo y el villismo, compuestos por indíge as y mestizos, el hálito justiciero y reividicador de la Revolución, todo conspiraba en favor de la corriente mestizófila. Mezcla de romanticismo redentor y realismo progresista: el muralismo, la novela de la revolución y la 
música nacionalista eran el reflejo artístico del despertar de la conciencia colectiva sin tapujos. De la intelectualidad se pasó a la búsqueda de las raíces; frente a las oleadas patrióticas de la Independencia, del despojo de 1847 o la Intervención francesa, surgidas como reacción a las intromisiones extranjeras, el sentimiento revolucionario era de introspección; la nueva ideología quería factores de cohesión con los que unificar el país y el mestizaje era el más apropiado. Aunque Luis Cabrera significó el último mestizófilo evolucionista, que no aprovechó las doctrinas relativistas que acompañaron al proceso revolucionario.

Entre los autores posteriores a Molina Enríquez, Manuel Gamio en su búsqueda de la homogeneidad social halló en el mestizaje el hilo conductor. La falta de unidad étnica y de identidad cultural es lo que hace a las naciones. Sólo si al indio se le acerca al nivel del criollo podrá tener lugar un día el proceso de fusión étnica de la población y México podrá convertirse en una nación. Es el primer indigenista dentro de la corriente mestizófila. Pretende que los indios desaparezca, mejor, que se reencarnen en mestizos para que quede algo de ellos. Sólo así el indio puede colarse en la modernidad, en el México urbano e industrial que empieza a gestarse en la Revolución. Para salvaguardar al indígena y mientras no haya un mismo criterio en materia de arte éste deberá conservar el suyo y adoptar sólo la ciencia occidental, porque produce resultados más prácticos, por lo que se refiere al bienestar material e intelectual. Tener arte y no ciencia es síntoma de desequilibrio cultural, no de inferioridad racial. La relación raza-cultura es fundamental para comprender su tesis. Por primera vez se propone el mestizaje cultural, como un importante catalizador de la fusión étnica y como su imprescindible producto. Representa la conciliación del romanticismo herderiano con su pragmatismo anglosajón; y combina sus influencias del relativismo cultural (Boas) con resabios evolucionistas (positivistas del Porfiriato). Después de Molina es el precursor del nacionalismo cultural de la revolución mexicana.

José de Vasconcelos, portavoz de la unificación mestizoamericana: de la mezcla mundial de razas no podrá salir, nada más que por selección de todas ellas, un nuevo tipo, la quinta raza universal, en América Latina, y la tienen en consideración porque el mestizaje tiene una avasalladora realidad. Sus premisas teóricas son: a) de carácter evolucionista (los tres estados sociales, material, intelectual y espiritual, de la necesidad al gusto, ésta la de la raza cósmica; y b) su interpretación histórica en base a la pugna latinidad-sajonismo. Es una mestizofilia relativa, más bien una hispanofilia amestizada. En un segundo momento, con el fracaso político, reniega de su mestizofilia en pro de un criollismo. Si antes la había aceptado era porque el proceso de mestizaje era un hecho, inevitable e irreversible. Se resiente del positivismo de Comte aunque sea más espiritualista, y en la desaparición natural de los menos fuertes recuerda a Darwin y Spencer. La idea del gusto es intuicionista, no ha desaparecido del todo la influencia del positivismo. Su tesis de raza cósmica no tiene propósito de justicia social, pero eleva el mestizo a rango universal. Exhorta a no copiar modelos a crear. Con él acabó la corriente etnocentrista, cuya caída había acelerado ya el influjo introspectivo de la revolución y su impulso creativo, fruto de la guerra civil de 1910. El grupo Hiperión, 1949, de «México y lo mexicano» de Leopoldo Zea y otros aceptaba el mestizaje, pero no se hacían ya propuestas. Se había producido una crisis de identidad, al no querir ser ni uno indio ni español (Octavio Paz), o una actitud optimista (Leopoldo Zea), que no ve problema ni en el mestizaje cultural, ni en las dosis asimétricas del mismo; para Santiago Ramírez las cosas son complicadas al nivel psicológico: el complejo de las dos culturas india y española. Otros dicen que no existe el mexicano típico, que le interesa a la cultura dominante para explotar a la otra (Roger Batra); otros que el mestizaje camina hacia su cabal maduración (el padre del autor).

A modo de conclusión, Besave plantea para un análisis posterior de la nueva mestizofilia dos nuevas variables: el afianzamiento del enfoque cultural del mestizaje a costa de su antigua preocupación por lo racial; percepción del sincretismo cultural como algo tan ostensible como irremediable o benefactor que camino solo hacia su culminación. La fusión cultural no avanzó como la étnica y aunque ello hace pensar en la inercia del mestizaje racial, no se puede pensar otro tanto de inercia para el cultural. El mestizaje actualmente ha pasado a segundo plano y mientras los europeos buscaban el elemento que les separaba y les hacía ser naciones, los autores mexicanos estudiados trataban de encontrar el elemento de unificación. Se jugó con la ventaja de la autopercepción mestiza de la intelectualidad mexicana, entre otras cosas porque no resultaría serio en México un análisis de la realidad que se hiciera sin contar con el componente étnico. No hay que olvidar, por otra parte, que la correlación clase-raza sigue presente en la actualidad, que la revolución contribuyó a disminuir, pero que no eliminó y sigue como sedimento cultural racista, sin que se haya consumado, por lo tanto, el mestizaje cultural.

La propuesta de Besave consiste en mestizar la cultura, limando las asimetrías para generar una conciencia nacional; también la economía, cuya asimetría es característica del subdesarrollo. Que se camine hacia la justicia social rescatando al indio de su clandestinidad para crear una nación única, nueva, no la suma de las anteriores.

Ante la modernidad como la que propone Occidente, México sólo tiene una salida: abrirse recíprocamente si la apertura enriquece, que ello producirá algo mejor. Aceptando el pasado indio-hispánico y añadiendo libertad y creación se construirá una gran nación, una sociedad libre y justa.

Desde el punto de vista histórico, Besave analiza la mestizofilia durante el México liberal, el de la Intervención francesa, la República, el Porfiriato, el de la Revolución y el Postrevolucionario. Abre un apartado para las nuevas tendencias.

Constituye el presente libro una aportación de notable interés para los estudiosos no sólo del mestizaje, sino del indigenismo y el criollismo. En su paseo breve, profundo y minucioso sobre el pensamiento de los principales teóricos de la 
corriente mestizófila en México, en el que se puede ver el reflejo que el pensamiento europeo positivista y, en el caso de Molina Enríquez, también el determinismo justiciero del marxismo mediante la aplicación que él hace de la lucha de clases a las razas, ha tenido en México y su aplicación al tema que Besave ha tratado. El personaje estudiado con más profundidad revela la vigencia y el interés actual del tema, a distancia de más de un siglo.

Como algunos de los pensadores analizados, Besave sigue proponiendo el tema del mestizaje como una meta aún por alcanzar, que no se puede dejar al devenir histórico sin colaborar en forzarlo.

Teresa García Giráldez

\title{
LA CEPAL EN LOS AÑOS NOVENTA: UN ENFOQUE RENOVADO DEL DESARROLLO.
}

\author{
CEPAL (1990), Transformación productiva con equidad. La tarea prioritaria del desarrollo \\ de América Latina en los años 90, Santiago de Chile, 185 págs.
}

CEPAL (1991), El desarrollo sustentable: transformación productiva, equidad y medio ambiente, Santiago de Chile, 146 págs.

CEPAL (1992), Equidad y transformación productiva: un enfoque integrado, Santiago de Chile, 254 págs.
CEPAL/UNESCO (1992), Educación y conocimiento: eje de la transformación productiva con equidad, Santiago de Chile, 269 págs.

En los años 50 y 60 la Comisión Económica para América Latina de las Naciones Unidas (CEPAL) formuló un conjunto de propuestas de política económica basado en el estructuralismo, coindiciendo con el período en el que Raúl Prebisch fue Secretario Ejecutivo de la Comisión (1948-1962), y que fue conocido como «el enfoque de la CEPAL» o el «modelo de sustitución de importaciones». Dicho modelo fue adoptado por muchos gobiernos como «doctrina oficial» del desarrollo nacional - aunque la aplicación concreta fue a menudo muy distinta - y dio sustento a una larga etapa de crecimiento económico, modernización productiva y cambio social.

En los 80, sin embargo, fue visible tanto el agotamiento del modelo como la crisis de las ideas en las que éste se basó. La crisis significó el retorno a la ortodoxia y la aplicación de estrictas políticas de estabilización, ajuste estructural, libealización y apertura comercial, inspiradas por el pensamiento neoliberal y en gran medida impulsadas por el Fondo Monetario Internacional. El neoliberalismo cuestionó el modelo de crecimiento propugnado por la CEPAL, que a pesar de no coincidir frecuentemente con las políticas económicas «reales» de los gobiernos, fue considerado a menudo como responsable directo de la crisis. Las críticas, sólidamente afianzadas en hechos muy visibles, se centraron en el exceso de protección, causa de la ineficiente asignación de recursos y de la falta de competitividad: en el "sesgo antiexportador» y «antiagrícola» del modelo, en la subestimación de las políticas de corto plazo, en especial la monetaria; en los desequilibrios crónicos y la tolerancia hacia el déficit fiscal y comercial, y por último en el exceso de intervención estatal, la mala gestión y la expansión exagerada del sector público. El criticismo a la CEPAL y la «sustitución de importaciones» pronto trascendió lo académico y se impuso en otros ambientes, en versiones a menudo doctrinarias, devaluadas y ahistóricas, ignorando que Prébisch y la propia CEPAL habían alertado ya en los años 60 sobre estos mismos problemas y, algo más obvio, que se cuestionaban desde las experiencias de la crisis ideas formuladas en un contexto histórico muy distinto, hacía ya dos décadas.

Ante la ofensiva ideológica monetarista, los años 80 han sido para la CEPAL y el pensamiento estructuralista un período de confusión y pesimismo, pero también un espacio para el aprendizaje, la reflexión crítica y el análisis empírico de experiencias de desarrollo más exitosas. A mediados de la década surge, en este clima, el enfoque «neoestructuralista». Este se centró inicialmente en la crítica de los programas de ajuste, proponiendo alternativas compatibles con el crecimiento y la equidad, así como en la revisión crítica del estructuralismo y sus insuficiencias. Superando el corto plazo, esta corriente pronto adoptó un enfoque estratégico. Se recuperaron elementos aún valiosos del traadicional, «enfoque de la CEPAL», como la importancia de la industrialización, el Estado y las políticas selectivas para la incorporación del progreso técnico, pero como parte del «aprendizaje doloroso» de la crisis se concedió más atención a los equilibrios macroeconómicos y al control de la inflación, y se superaron otras insuficiencias teóricas incorporando el enfoque sistémico de la competitividad, la dimensión ambiental del desarrollo o la reforma del Estado. Finalmente, el análisis consideró el nuevo escenario internacional, en el que la revolución tecnológica y la inestabilidad del mercado mundial imponen nuevas condiciones a la inserción de las economías de la región, ante las que es necesario un buen desempeño exportador y una redefinición de las modalidades de integración regional. En suma, se consideró necesaria una nueva estrategia de desarrollo «desde dentro», ya que ni la simple reedición del estructuralismo —el «desarrollo hacia adentro»— ni la continuación del neoliberalismo - desarrollo «hacia afuera»— podrían ya dar respuesta a los problemas de la Región. 
De estas reflexiones surgen las propuestas presentadas por la CEPAL en los documentos que reseñamos. El primero de la serie, Transformación productiva con equidad. La tarea prioritaria del desarrollo de América Latina en los años 90 , representó un punto de inflexión en el clima de pesimismo de los años anteriores. Por primera vez tras el comienzo de la crisis, la CEPAL presentaba un documento propositivo global, con estrategias de largo plazo y políticas concretas, capaz de generar consensos entre los gobiernos, las fuerzas sociales y los actores económicos. El documento debía buena parte de su contenido a las reflexiones de Fernando Fajnzylber, funcionario de CEPAL ya fallecido, y a sus observaciones de la experiencia del Sudeste asiático, que ilustraban la compatibilidad y, aún más, la mutua necesidad de crecimiento y equidad, de industrialización sustitutiva y competitividad externa, del auge exportador y la incorporación de tecnología, y del libre juego del mercado con la intervención selectiva del Estado. El objetivo de Transformación productiva... es definir una estrategia de desarrollo basada en la transformación a largo plazo de las estructuras productivas y la mejora de la competitividad internacional en la región en un marco de creciente equidad social. Según CEPAL, la competitividad debiera sostenerse más en la incorporación deliberada y sistemática del progreso técnico — competitividad «auténtica»-y menos en la depreciación de los salarios o en el agotamiento de los recursos naturales - competitividad «espuria»- La equidad sería, en este contexto, no sólo un imperativo ético y político - necesario para consolidar la democracia-, sino una necesidad económica, ya que sólo la inversión en recursos humanos, principalmente en salud y educación, hará posible sostener un «estilo» de desarrollo basado en la incorporación de tecnología. Ello permitiría de forma simultánea superar la crisis, lograr el crecimiento sostenido, reducir la desigualdad y preservar el medio ambiente. CEPAL reconoce que se trata de «un cúmulo extraordinario de exigencias», cuyo éxito dependerá de factores difíciles de controlar y de evolución incierta. En el plano externo se mencionan el grado de apertura y dinamismo del mercado internacional, la reducción de la deuda y las condiciones de acceso a la tecnología. En el plano interno, los esfuerzos nacionales para controlar los desequilibrios macroeconómicos y en especial la inflación, incrementar la inversión, reducir la pobreza y reforzar la cohesión social.

Los otros documentos desarrollan aspectos específicos de la propuesta. El desarrollo sostenible..., publicado en 1991 en preparación de la «Cumbre de Río», da por superada la falsa contraposición entre medio ambiente y desarrollo, y muestra la necesidad de la transformación productiva y la equidad para superar un patrón de exportaciones aún basado en la explotación intensiva de los recursos naturales, y para evitar el deterioro ambiental asociado a la pobreza. Sin embargo, CEPAL incursiona aquí en problemas muy controvertidos y con evidencias empíricas aún débiles, lo que se refleja en la menor elaboración de algunas propuestas y del marco analítico.

Más consistentes y persuasivos son, sin embargo, los dos documentos publicados en 1992, Equidad y transformación productiva: un enfoque integrado señala, a la luz de la experiencia de la región, que el crecimiento no genera por sí solo equidad, restando validez a la conocida tesis del «derrame». El documento, frente a lo que se sostuvo en el pasado, descarta también que la política racial, por sí sola, sea garante de la equidad. Una de las enseñanzas del ajuste de los 80 ha sido precisamente que una política económica regresiva en materia de empleo o de rentas tiene consecuencias sociales que a menudo superan los efectos distributivos progresivos de la política social. Por si esta razón no fuera suficiente para justificar un enfoque integrador hacia las políticas encaminadas al crecimiento, por un lado, y a la equidad, por otro, ha de añadirse el efecto productivo y de eficiencia que tiene la equidad sobre la economía. Algunas de las orientaciones estratégicas que sugiere la CEPAL en este contexto son la mejora de las coberturas y de la calidad de la salud, la seguridad social y la educación, como una forma de inversión en los recursos humanos funcional al desarrollo, además de programas de transferencias de corto plazo - empleo de emergencia, fondos de inversión social—. Estos, en conjunto, permitirán, según la CEPAL, romper el «círculo vicioso» de la pobreza, por el cual ésta se transmite de una generación a otra. Atención especial se concede al fortalecimiento de las finanzas públicas, a fin de financiar el relanzamiento de la política social. En el marco del ajuste, a menudo se logró reducir el déficit fiscal recortando drásticamente el gasto social. Para los 90, CEPAL sugiere prestar atención a otras partidas de gasto, como el militar, y reforzar los ingresos, habida cuenta de la regresividad que caracteriza a la mayor parte de los sistemas fiscales de la región. Ello, unido a una mayor eficiencia en la asignación del gasto público social, harían posible según CEPAL enfrentar el desafío de la equidad.

En esta dirección avanza Educación y conocimiento: eje de la transformación productiva con equidad, publicado en 1992 por la CEPAL y la UNESCO. A diferencia de los textos anteriores, Educación y conocimiento... contiene un detallado anàlisis del coste y financiamiento de las medidas necesarias para modernizar la educación, mejorar su calidad, universalizar el acceso y extender la formación profesional. Para la región en su conjunto, ello supondría añadir al actual 7\% del PIB regional destinado a educación un 3,9\% adicional, alcanzando así niveles equiparables a los de países industrializados. CEPAL y UNESCO plantean que estos objetivos son realizables, siempre y cuando sea posible abordar una reforma fiscal progresiva, reasignar los cuantiosos recursos destinados a la defensa - que representa en torno al $2 \%$ del PIB regional- utilizando así el «dividendo para la paz», o al pago del servicio de la deuda externa — que supera el 3\%-. Finalmente, está prevista la aparición a finales de 1993 de un nuevo documento de esta serie, centrado en la integración regional, en el que CEPAL aboga por un «regionalismo abierto» que compatibilice procesos de integración subregional con la estrategia de apertura comercial.

Superando el pesimismo y la crisis de ideas y de proyectos de futuro de la década anterior, la propuesta de la CEPAL, con sus aciertos y limitaciones, permite al pensamiento latinoamericano recuperar un lugar destacado en el debate interna- 
cional sobre el desarrollo. Nos encontramos, por ello, ante documentos de indudable importancia para el futuro de la región y de obligada referencia para el analista. La detallada investigación empírica que contienen, su carácter global y comprehensivo, la ausencia de ideologismos, la incorporación de las enseñanzas de la crisis y la inclusión de objetivos factibles, son los principales valores que hacen atractivo el nuevo planteamiento de la CEPAL, y que permiten augurar que la estrategia propuesta tendrá una cierta influencia en los gobiernos de la región. Sin embargo, sería aventurado garantizar el éxito de la propuesta sólo a partir de su capacidad explicativa y propositiva. En primer lugar, los condicionantes externos son aún determinantes, como señaló el propio Secretario Ejecutivo de la CEPAL, Gert Rosenthal, ante la última Cumbre Presidencial del Grupo de Río el 16 de octubre de 1993: «En los años 80, acaso era atendible el argumento de que una mejor gestión económica podía conducir a progresos importantes en el desempeño global de las economías. En la actualidad, ese argumento resulta menos convincente [...] En general, las economías latinoamericanas están mucho más abiertas al comercio internacional y, en cierta forma, su suerte depende más que antes del comportamiento de sus respectivos sectores externos». En este sentido, un factor determinante es el logro de una reducción sustancial de los niveles de endeudamiento, así como la superación de la inestabilidad y la atonía que sigue caracterizando el escenario económico internacional. Pero las dificultades más grandes se encuentran, posiblemente, en el plano de la política interna, un terreno en el que la CEPAL se ha abstenido deliberadamente de incursionar en esta serie de documentos. Las dificultades y obstáculos internos de orden político - en particular la resistencia de los sectores tradicionales de poder-para reducir los presupuestos de defensa, abordar una reforma fiscal progresiva o emprender la reforma del Estado, pueden ser insalvables en muchos países, o bien mucho mayores que las dificultades que han llevado consigo las reformas asociadas al ajuste, como la apertura comercial o la privatización de activos públicos.

José Antonio Sanahuja Perales 